\title{
EL CASTELLANO Y LAS DEMÁS LENGUAS ESPAÑOLAS
}

\begin{abstract}
Resumen. Basándonos en el artículo $3^{\circ}$ de la Constitución Española vamos a abordar la temática relacionada con los conceptos de castellano, español, lenguas españolas y modalidades lingüísticas. En primer lugar, averiguaremos las diferencias entre los términos español y castellano según diversas fuentes de consulta. En segundo lugar, mencionaremos los criterios que diferencian los términos lengua, dialecto, habla, variante y modalidad. Por último, presentaremos el vasto panorama lingüístico de España, enumerando y describiendo brevemente 5 lenguas cooficiales y 9 modalidades lingüísticas.
\end{abstract}

Palabras clave: Plurilingüismo de España, términos castellano y español, lenguas cooficiales, modalidades lingüísticas.

Dedico el presente artículo a un gran conocedor de las lenguas románicas, al Profesor Wiaczesław Nowikow, así como las siguientes palabras de Honoré de Balzac «Lo que el genio tiene de bello es que se parece a todo el mundo y nadie se le parece» (Laâbi, 2007: 201).

Según el Informe del año 2017 elaborado por el Instituto Cervantes (2017: 5), el español «es la segunda lengua materna del mundo por número de hablantes, tras el chino mandarín, y también la segunda lengua en un cómputo global de hablantes (dominio nativo + competencia limitada + estudiantes de español)». Además, el español es la lengua oficial de veintiún países, por lo que se convierte en la lengua neolatina más hablada del mundo. Se originó en España, entre otras lenguas que convivían por aquel entonces. Hoy en día el español tampoco es única lengua hablada en el territorio español. De hecho, se puede constatar que España, desde sus comienzos, siempre ha sido un país plurilingüe. Dicha pluralidad lingüística está plenamente reconocida en la Constitución Española de 1978 en el artículo $3^{\circ}$ titulado El castellano y las demás lenguas españolas:

\footnotetext{
* Uniwersytet Mikołaja Kopernika w Toruniu.
} 
1. El castellano es la lengua española oficial del Estado. Todos los españoles tienen el deber de conocerla y el derecho de usarla.

2. Las demás lenguas españolas serán también oficiales en sus respectivas Comunidades Autónomas de acuerdo con sus Estatutos.

3. La riqueza de las distintas modalidades lingüísticas de España es un patrimonio cultural que será objeto de especial respeto y protección.

Como se puede notar, en la Constitución Española se hace mención explícitamente solo de una lengua en concreto, o sea, del castellano, subrayando que «es la lengua española oficial del Estado». El nombre castellano aparece aquí como sinónimo de la lengua española, mientras que el término lengua española es empleado para representar otros idiomas hablados en el territorio del Reino de España aunque no se los enumera.

Así las cosas, el objetivo del presente trabajo será doble: por un lado, averiguar las diferencias entre los términos castellano y español; y por otro, enumerar las lenguas que actualmente se hablan en España y que conviven con el castellano como lenguas cooficiales o como modalidades regionales.

Detengámonos, por tanto, para investigar el significado de los términos castellano y español, recurriendo primero al Diccionario de la Real Academia Española:

español m. Lengua romance que se habla en España, gran parte de América, Filipinas, Guinea Ecuatorial y otros lugares del mundo.

castellano m. Lengua española, especialmente cuando se quiere distinguir de alguna otra lengua vernácula de España.

Como vemos, el término español se define como lengua romance que se habla en los concretos lugares del mundo, sin que aparezca el término castellano como su sinónimo. En cambio, el término castellano sí se define como lengua española, por lo que constituye su sinónimo, aunque su uso se recomienda para casos especiales, o sea, cuando se quiere distinguir la lengua española de cualquier otra lengua autóctona de España.

En todo caso, poner el signo de igualdad entre los dos términos es respaldado por autores tales como Quesada Marco (2010: 10), quien explica que «al español se le denomina también castellano, por Castilla, su región de origen. Este nombre lo distingue de las otras lenguas españolas», o Aguirre (2011: 126), quien precisa que «hoy en día, castellano y español se utilizan como sinónimos en muchas ocasiones; aunque en cierta medida deberíamos considerar que el castellano es la variedad de español que se habla en Castilla». 
Otro punto de vista lo encontramos en los estudios diacrónicos en los que, siguiendo a Cano Aguilar (2008: 11), esta dualidad terminológica resulta más conflictiva, por lo que se prefiere no mezclar ambas denominaciones. Medina López (2003: 80) aclara que:

Español -de etimología provenzal- se utiliza para referirse a la lengua general de España que es hablada por millones de hablantes fuera de las fronteras administrativas españolas y que, además, es la lengua también oficial de casi todos los países de Hispanoamérica [...].

Castellano ha quedado, en buena medida en la actualidad, restringido a la vertiente histórica del nombre de la lengua. Por supuesto, hace referencia al origen de la misma (habla propia de Castilla y de los castellanos), si bien esto no siempre ha sido así a lo largo de la historia de estos nombres. Castellano es un término menos amplio que español [...].

El hecho de que castellano sea un término menos amplio y menos empleado que español se debe en gran medida a la Real Academia Española, fundada en el año 1713, con la finalidad de fijar y poner las normas ortográficas de la lengua española bajo el lema principal «limpia, fija y da esplendor a la lengua española» (Aguirre, 2011: 126 y 152). Como salta a la vista, la Academia favoreció el nombre español en su vocabulario en detrimento de castellano. Tanto en el mismo nombre de la institución como en su lema se evita el término castellano y se abre así el período del español moderno que va desde el siglo XVIII hasta la actualidad.

Por otra parte, siguiendo a Pinzón Camargo (2006: 112), cabe mencionar también que en otros países hispanohablantes ambos términos se emplean indistintamente como sinónimos. Esta alternancia es percebible, por ejemplo, en las Constituciones, puesto que las de Panamá, Nicaragua, Honduras, Guatemala, Costa Rica y Cuba emplean el término español, mientras que las de Colombia, Venezuela, Ecuador, Perú y Paraguay optan por el término castellano.

Cabe por tanto acentuar que, a pesar de todas las definiciones y enfoques presentados supra, el uso de los términos castellano y español puede en ocasiones basarse simplemente en las razones afectivas, y «contra ellas no hay argumentos; la razón está allí donde el hablante quiere encontrarse: unos se identifican con castellano, otros con español, otros con ambas designaciones de su lengua» (Alvar, 1991: 85-86).

Volvamos ahora a los arriba enumerados puntos 2 y 3 del artículo $3^{\circ}$ de la Carta Magna de España. En ellos se menciona que las demás lenguas españolas serán cooficiales junto al castellano, siempre y cuando se las reconozca como tales en los Estatutos de las respectivas Comunidades 
Autónomas, y que las distintas modalidades lingüísticas de España serán respetadas y protegidas como un patrimonio cultural.

Desde el punto de vista terminológico, como vemos, destacan en la Constitución dos términos lenguas y modalidades lingüísticas. Describámoslos brevemente. Así pues, por lengua entendemos, tras Alvar (1982: 60):

[...] el sistema lingüístico del que se vale una comunidad hablante y que se caracteriza por estar fuertemente diferenciado, por poseer un alto grado de nivelación, por ser vehículo de una importante tradición literaria y, en ocasiones, por haberse impuesto a sistemas lingüísticos de su mismo origen.

En cambio, el término modalidad se usa en la dialectología como sinónimo de hablas regionales y no como sinónimo de dialecto. Como aclara Calderón Campos (2001: 29):

En el ámbito de la lengua española podemos distinguir, en un primer acercamiento, entre hablas o modalidades regionales, por una parte, y dialectos regionales o simplemente dialectos, por otra. Las hablas o modalidades regionales presentan particularidades fonéticas y, secundariamente, léxicas, mientras que los dialectos, además de las citadas diferencias, muestran otras de carácter morfosintáctico.

346 A su vez, De Cos Ruiz (2006: 57) subraya que, para que una modalidad lingüística o dialecto alcancen el rango de lengua, tienen que imponerse a otros sistemas lingüísticos de igual origen, como lo hizo antaño el romance castellano arrinconando al aragonés y al leonés y eliminando al mozárabe y al riojano. Cabe, por tanto, advertir que el concepto de lengua incluye sobre todo prestigio político, social y demográfico, puesto que es un sistema lingüístico adoptado por un estado, es de validez colectiva y tiene un considerado número de usuarios. Tomándolo en consideración, no parecerá excesivo afirmar, siguiendo a Rodríguez Adrados (2008: 269), que «los conceptos de 'lengua', 'dialecto' y 'variante' no son propiamente de orden lingüístico, sino de orden social y aun político», por lo que a continuación dejaremos de lado las posibles polémicas terminológicas y nos concentraremos en enumerar las demás lenguas españolas y modalidades lingüísticas tal como las recopilamos de las fuentes consultadas.

Así pues, las demás lenguas españolas cooficiales junto al castellano que figuran en los Estatutos de sus respectivas Comunidades Autónomas son el catalán, el valenciano, el aranés, el gallego y el euskera.

En cuanto al catalán, es una lengua románica, emparentada en su origen con el provenzal, que no constituye una lengua unificada. Se divide, por tanto, en dos grandes bloques dialectales: en el bloque oriental y en 
el bloque occidental (VV.AA., 2010: 9). Las diferencias entre la variante oriental y occidental del catalán son considerables y atañen ante todo a la pronunciación, la conjugación de ciertos tiempos verbales y el léxico. Los dialectos del bloque oriental se hablan en las provincias de Barcelona, en Girona, en el este de Tarragona y en las islas Baleares. En cambio, los dialectos del bloque occidental se hablan en las provincias de Lleida, en el resto de Tarragona y en la Comunidad Valenciana. Cabe resaltar que, en esta última comunidad, dicho dialecto es conocido como el valenciano.

En lo concerniente al aranés, es un occitano hablado entre los habitantes del Valle de Arán, en Cataluña, en la provincia de Lleida. Como explica González i Planas (2002: 76), «es el resultado de la particular evolución de la lengua latina en aquel territorio después de su proceso de romanización. En términos dialectológicos, el occitano del Valle de Arán pertenece a la rama pirenaica de los dialectos gascones». Cabe asimismo subrayar que los ciudadanos del Valle de Arán son trilingües: usan como lenguas oficiales el aranés, el español y el catalán.

Respecto al gallego, es importante recordar, tras Rodríguez Adrados (2008: 276), que antes del año 1139, fecha en la que se independiza Portugal, el portugués y el gallego eran una misma lengua romance, llamada galaicoportugués. La huella del parentesco entre ambas lenguas queda muy visible, verbigracia, en la conversión de la $p l$ - latina inicial en $c h-$. Así, de la palabra latina pluvia (en español, lluvia) derivan las palabras portuguesa chuva y la gallega choiva. Según las recopilaciones de Carbolová (2009: 8-9), hoy en día se habla gallego en toda Galicia y «en los límites con las comarcas de Asturias, León y Zamora que históricamente pertenecían a la antigua Gallaecia».

Por lo referente al euskera, también llamado vasco, vascuence, euskara, conforme con Sawicki (1993: 123), se habla en el País Vasco, en Navarra y en las tres históricas provincias vascas de Francia. Se divide en ocho dialectos euskéricos bastante diferenciados entre sí, que se usan en siete territorios -cuatro españoles y tres franceses-que forman Euskal Herría ${ }^{1}$. No obstante, todos estos dialectos se han refundido en una sola lengua literaria: vascuence unificado, denominado Euskara Batua. Como señala López-Mugartza Iriarte (1987: 7), el euskera es una lengua tan antigua que incluso ha sido testigo del nacimiento y muerte del latín, idioma del que procede el castellano. Sin embargo, su origen sigue siendo incógnita, aunque no faltan hipótesis para desentrañarla.

${ }^{1}$ Cabe explicar, tras Sawicki (1993: 138), que con el nombre Euskal Herría los vascos designan el conjunto de su territorio dividido entre España y Francia. Viene de las palabras eusca, que significa vasco, y herri, que significa pueblo. 
Ahora bien, entre las modalidades lingüísticas que hoy en día se hablan en España y que forman parte de su vasto patrimonio cultural podemos distinguir el aragonés, el asturiano, el extremeño, el gallego de Extremadura, el leonés, el murciano, el canario, el andaluz y el caló.

Según los datos aportados por Quesada Marco (2010: 10-11), el aragonés, también llamado fabla, es hablado por los habitantes de los valles pirenaicos de Aragón. Sus hablantes, no obstante, prefieren denominar la variante que hablan con el nombre del valle en el que viven. Lo mismo sucede con el término asturiano, puesto que se prefiere la denominación bable ${ }^{2}$ para referirse a esta modalidad lingüística. Además, su forma plural, los bables, muy corrientemente usada por los hablantes, testimonia su diferenciación en hablas locales.

En Extremadura, además del dialecto extremeño, «que está desgajado del dialecto leonés» (Viudas Camarasa, 1976: 123), se habla también el gallego de Extramadura, conocido más bien como a fala o a fala de Xálima. En palabras de Dondelewski (2014: 65-66), «es un geolecto de raíces galaico-portuguesas y astur-leonesas, resultante de la amalgama primitiva de hablas de colonos de diversas procedencias, asentados allí durante la reconquista (s. XII)». Se habla en tres localidades del Val de Xálima, en la provincia de Cáceres, en la frontera luso-española.

En cuanto al leonés, hablado en las provincias de León, Zamora y Salamanca, cabe recordar que, igual que el castellano, procede del latín vulgar y durante varios siglos era «la lengua predominante en la España cristiana desde la frontera con Francia a Galicia, y llegando hacia el sur hasta Andalucía» (García Álvarez, 1983: 84).

Por lo referente al murciano, como advierte Gómez Ortín (2004: 8), «la estructura morfológica y la construcción sintáctica son iguales que en todo el dominio del español», aunque posee sus particularidades como cualquier otra variante regional. Dicho autor lo ejemplifica:

[...] con el uso de los diminutivos, cuyas variantes sufijales caracterizan a las distintas hablas regionales. Si los gallegos emplean el -iño, los asturianos el -in, los montañeses el -uco, los leoneses y extremeños el -ino, los castellanos el -ito, los andaluces el -illo (-iyo) y los manchegos el -ejo y el -ete, ¿por qué los murcianos no podemos usar el -ico, junto con los navarros y aragoneses y también con los "ticos" o costarricenses? (Gómez Ortín 2004: 8)

En lo concerniente al canario, según Díaz Alayón (1990: 31), este «posee unas características similares a las variedades meridionales de la

${ }^{2}$ Winkelmann (1994: 10) añade que: «De la expresión bable, que originariamente significaba 'balbuceo, tartamudeo', se puede fácilmente deducir el hecho de que, hasta ahora, la lengua no ha gozado de un alto prestigio frente a la lengua nacional». 
Península y se acerca de modo especial al español de América». Pongamos como ejemplo el uso de la forma ustedes en vez de vosotros, la sustitución del posesivo vuestro / vuestra por de ustedes y la ausencia de la oposición de $/ \mathrm{s} / \mathrm{y} / \theta /$.

Respecto al andaluz, según Cano Aguilar (1992: 52-55), es una modalidad dialectal que nació en el Reino de Sevilla, especialmente, a lo largo del siglo XV. En el plano fonológico, destaca sobre todo la indistinción de $/ \mathrm{s} /$ y $/ \theta /$ y la pronunciación aspirada de la jota y de ciertas palabras escritas con $h$-. Las diferencias gramaticales entre el habla andaluza y el castellano atañen meramente al empleo de los pronombres y a la reducción del uso de vosotros.

En cuanto al caló, Chamorro et al. (2011:47) precisan que es una lengua mixta que se basa en la gramática española, pero que incluye mucho vocabulario procedente del romaní. Es la lengua de la comunidad gitana, hablada en todo el territorio español, pero principalmente en Andalucía, Madrid y Cataluña. Sus hablantes constituyen la mayor minoría étnica española.

Para terminar, citemos a Samuel Johnson, un escritor inglés del siglo XVIII, quien dijo: «En el idioma está el árbol genealógico de una nación» (Laâbi, 2007: 178). Así pues, a la vista del plurilingüismo de España, no cabe la menor duda de que los españoles forman una nación no de un solo árbol genealógico, sino de una verdadera arboleda.

\section{Bibliografía}

AGUIRRE, C. (ed.) (2011). El mundo en español. Lecturas de cultura y civilización. Madrid: Imprimex.

ALVAR, M. (1982). La lengua como libertad y otros estudios. Madrid: Instituto de Cooperación Iberoamericana.

ALVAR, M. (1991). El español de las dos orillas. Madrid: Mapfre.

CALDERÓN CAMPOS, M. (2001). «Los conceptos de modalidad regional, dialecto y variedad estándar en la delimitación de las variedades del español», en D. ESTÉBANEZ CALDERÓN (ed.), El hispanismo en la República Checa. Praga: Univerzita Karlova.

CANO AGUILAR, R. (1992). «Algunas reflexiones sobre la lengua española en Andalucía», Cauce, 14-15, 47-60.

CANO AGUILAR, R. (2008). El español a través de los tiempos, $7^{\text {a }}$ edición. Madrid: Arco Libros.

CARBOLOVÁ, K. (2009). La situación sociolingüística de Galicia, Memoria de licenciatura bajo la tutoría de Ivo Buzek. Brno: Masarykova Univerzita. 
CHAMORRO, C., MARTÍNEZ, M., MURILLLO, N. y SÁENZ, A. (2011). Todas las voces. Curso de cultura y civilización. Barcelona: Difusión.

CONSTITUCIÓN ESPAÑOLA [en línea] <http://www.lamoncloa.gob.es/documents/constitucion_es1.pdf $>$, fecha de consulta: 23 de abril de 2018 .

DE COS RUIZ, F. J. (2006). «Las Variedades lingüísticas en la enseñanza de E / LE: Aplicación a la modalidad oral andaluza», redELE, vol. 3, 6, 53-76.

DÍAZ ALAYÓN, C. (1990). «Los estudios del español de Canarias», THESAURUS, t. XLV, 1, 31-62.

DONDELEWSKI, B. (2014). «'Éste no habla como yo'. Algunas cuestiones metodológicas acerca del estudio de la percepción popular de la variación geolectal en relación con a fala de Xálima (Cáceres)», en J. PAWLIK y J. SZAŁEK (eds.), Lingüística española en Polonia: líneas de investigación. Poznań: Wydawnictwo Naukowe UAM, 65-74.

GARCÍA ÁLVAREZ, A. (1983). «El dialecto leonés: historia y perspectivas futuras», Tierras de León. Revista de la Diputación Provincial, vol. 23, 53, 82-96.

GÓMEZ ORTÍN, F. (2004). «El dialecto murciano y sus variedades», Revista electrónica de estudios filológicos, 8, 7-27.

GONZÁLEZ i PLANAS, F. (2002). «Era Val D’Aran: una comunidad lingüística aislada», IANUA, 2, 76-88.

INSTITUTO CERVANTES (2017). El español: una lengua viva. Informe 2017 [en línea] <https://cvc.cervantes.es/lengua/espanol_lengua_viva/pdf/espanol_lengua_viva_2017.pdf $>$, fecha de consulta: 30 de abril de 2018.

LAÂBI, S. M. (2007). Citas y frases célebres. Selecta colección de citas con el pensamiento de los personajes célebres que han hecho historia. Madrid: Libsa.

LÓPEZ-MUGARTZA IRIARTE, J. C. (1987). Pamplona se dice Iruñea. Burlada: I. G. Castuera.

MEDINA LÓPEZ, J. (2003). Historia de la lengua española I. Español medieval. Madrid: Arco Libros.

PINZÓN CAMARGO, L. C. (2006). «La denominación de la lengua: ¿Castellano? o ¿Español?», Cuadernos de Lingüística Hispánica, 7, 111-118.

QUESADA MARCO, S. (2010). España. Manual de civilización E / LE. Madrid: Edelsa.

REAL ACADEMIA ESPAÑOLA. Diccionario de la Real Academia Española [en línea] <http://dle.rae.es>, fecha de consulta: 24 de abril de 2018.

RODRÍGUEZ ADRADOS, F. (2008). Historia de las lenguas de Europa. Madrid: Gredos.

SAWICKI, P. (1993). La España del cambio. Warszawa: PWN.

VIUDAS CAMARASA, A. (1976). «El dialecto extremeño», Boletín AEPE, 15, 123-131.

VV.AA. (2010). Catalán de cada día. Barcelona: Difusión.

WINKELMANN, O. (1994). «Sobre la estandarización de las lenguas minoritarias de España», Lletres Asturianes, 53, 7-17. 